\title{
Tree Ring Growth and Stable Isotopes as Potential Indicators of Historical Seabird Activities on Forested Islands in Coastal British Columbia
}

\author{
T. E. ReImCHEN ${ }^{1}$, S. McGeheE, and B. W. GLickMAN
}

Department of Biology, University of Victoria, P.O. Box 3020, Victoria, British Columbia V8W 3N5 Canada

${ }^{1}$ Corresponding author; email: reimchen@uvic.ca

Reimchen, T. E., S. McGehee, and B. W. Glickman. 2013. Tree ring growth and stable isotopes as potential indicators of historical seabird activities on forested islands in coastal British Columbia. Canadian Field-Naturalist 127(2): 146-154.

We examined yearly rings from increment cores of conifers on two seabird nesting islands (one in the Lucy Islands and one in the Rankine Islands, British Columbia), to determine whether trees contained signatures of historical activity of seabirds. Ten conifers (primarily Sitka Spruce, Picea sitchensis), ranging from $56 \mathrm{~cm}$ to $127 \mathrm{~cm}$ diameter (average $90 \mathrm{~cm}$ ) and ranging from 70 to 232 years in age (average 132 years of age), were cored across a 200-m gradient in densities of seabird burrows. At the site in the Lucy Islands, annual growth was highest $(8-14 \mathrm{~mm})$ in the trees with the highest seabird burrow densities and highest in the earliest rings $(\sim 1930)$, which were followed by a fluctuating reduction down to $\sim 2 \mathrm{~mm} /$ year in the year 2000 , but with a secondary elevated growth period in the 1970s. Adjacent control trees without seabird burrows had a growth rate of $\sim 2 \mathrm{~mm}$ /year throughout the same period. At the site in the Rankine Islands, growth rates were also variable and exhibited a 10-15 year non-synchronous periodicity, with the highest growths in the location with high seabird burrow density. Nitrogen isotope signatures $\left(\delta^{15} \mathrm{~N}\right)$, which are greatly elevated in seabird guano, ranged from minus $3.9 \%$ to $17.4 \%$ among tree rings $(n=245$ rings) and were positively correlated to percentage nitrogen in rings, average ring growth, and burrow densities. Using these methods, we infer from our tree ring data that seabird activity declined on the Lucy Islands over a 70-year period and that the combination of growth, nitrogen isotopic signatures, and percentage nitrogen in tree rings as well a more detailed sampling grid of target and adjacent control trees will provide seabird biologists with additional tools for evaluating spatial and historical trends in seabird activity on forested islands.

Key Words: Alcidae; Picea sitchensis; Sitka Spruce; Rhinoceros Auklet; Cerorhinca monocerata; Cassin's Auklet; Ptychoramphus aleuticus; burrows; colony; historical activity; percentage nitrogen; stable isotopes; tree rings; British Columbia

Seabirds have a significant impact on terrestrial plant communities (reviewed in Ellis 2005). Elevated nitrogen levels as well as ${ }^{15} \mathrm{~N}$ enrichment are reported in soils and grasses from seabird colonies in California, as guano is greatly enriched in ${ }^{15} \mathrm{~N}$ (Mitzutani and Wada 1988; Anderson and Polis 1998; Wait et al. 2005). Values of $\delta^{15} \mathrm{~N}$ (ratio of ${ }^{15} \mathrm{~N} /{ }^{14} \mathrm{~N}$ in sample relative to air reference) from soil cores have been used to determine the length of time seabirds have occupied an area and to identify when a site was abandoned (Mitzutani et al. 1991; Hawke 2004). However, microsite differences in the extent of nutrient leaching and differences in the extent of microbial processing of nitrogen, as well as in the volatilization of nitrogen, appear to limit the general application of nitrogen isotopes as historical indicators of seabird activity (reviewed in Hart and Classen 2003).

Growth rates and stable isotope analysis of tree rings have been used to identify spatial and temporal trends in nitrogen cycling in forests (Bukata and Kyser 2007; Holdaway et al. 2007; Mizota 2009; Mizota et al. 2011). Large transfer of Chum Salmon (Oncorhynchus keta) biomass from streams to riparian zones by American Black Bears (Ursus americanus) in coastal British Columbia (Reimchen 2000) is associated with an uptake of these nutrients by riparian vegetation, as evidenced by the enrichment of $\delta^{15} \mathrm{~N}$ in foliar tissues (Reimchen 2001; Mathewson et al. 2003; Wilkinson et al 2005) and in tree rings (Reimchen et al. 2003). There is evidence of a correlation between $\delta^{15} \mathrm{~N}$ signatures in tree rings and recent numerical counts of Chum Salmon (Drake and Naiman 2007). Experimental application of a ${ }^{15} \mathrm{~N}$ tracer to simulate decomposition of Chum Salmon showed that Western Red Cedar (Thuja plicata) immediately utilized the tracer (Drake et al. 2006). Yet, variability in $\delta^{15} \mathrm{~N}$ enrichment can have multiple and diverse causes, including changes in precipitation and temperature (Handley et al. 1999), changes in the soil microbial use of the nitrogen pool (Robinson 2001), and translocation of nitrogen in the sapwood (Drake et al. 2006; Balster et al. 2009), all of which confound any simple proxy between $\delta^{15} \mathrm{~N}$ enrichment and temporal trends in nitrogen sources (Koopmans et al. 1997).

Alcids and storm-petrels (Oceanodroma spp.) nest in burrows on numerous small forested islands off the coast of British Columbia. The daily deposition of guano would increase over the nesting period, particularly for species such as Rhinoceros Auklet (Cerorhinca monocerata) and Cassin's Auklet (Ptychoramphus aleuticus), whose young are fed over an extended prefledging phase (Campbell et al. 1990). Forests around the rim of the northern Pacific Ocean are generally nitrogen-limited (Schulze et al. 1994), and we expected to observe substantial spatial heterogeneity in nitrogen uptake associated with the input of guano. 
During a coast-wide field survey of riparian vegetation on salmon rivers in British Columbia in September 2000 (Reimchen et al. 2003), we visited two small forested islands (one in the Lucy Islands and one in the Rankine Islands, Figure 1). Each island has a small nesting colony of alcids during spring (Rodway 1991; Reimchen, personal observation). We cored 12 conifers across a gradient in burrow densities to assess the potential application of tree rings in estimating relative seabird activity. In this paper, we describe radial growth patterns (years $\sim 1925$ to 2000 ), $\delta^{15} \mathrm{~N}$ signatures, and percentage nitrogen for a subset of years. We predicted that we would find elevated tree growth, enriched $\delta^{15} \mathrm{~N}$, and elevated percentage nitrogen from trees near high burrow densities relative to control trees in adjacent regions $(50-100 \mathrm{~m})$ without burrows.

\section{Methods}

The Lucy Islands site $\left(54^{\circ} 17^{\prime} \mathrm{N}, 130^{\circ} 37^{\prime} \mathrm{W}\right)$ is $15 \mathrm{~km}$ west of Prince Rupert, northern British Columbia. It has a colony of approximately 25000 Rhinoceros Auklets, with most burrows within $100 \mathrm{~m}$ of the shoreline (Rodway 1991; Gaston and Dechesne 1996). The Rankine Islands site $\left(52^{\circ} 19^{\prime} \mathrm{N}, 131^{\circ} 16^{\prime} \mathrm{W}\right)$ is $225 \mathrm{~km}$ southwest of Prince Rupert off the southeastern coast of Moresby Island in the Haida Gwaii archipelago. It has a mixed colony of Cassin's Auklet, Ancient Murrelet (Synthliboramphus antiquus), and Leach's Storm-Petrel (Oceanodroma leucorhoa). All species total 20000 , with most burrows occurring on the southeastern edge of the island (Lemon, personal communication).

On the two islands, we identified 15 of the largest trees (14 Sitka Spruce and 1 Western Hemlock, Tsuga heterophylla) and 2 Sitka Spruce saplings as size controls, each of which was cored. Twelve of the 17 trees yielded sufficiently intact cores for ring measurements. Circumference at breast height $(\sim 1.3 \mathrm{~m})$ (converted to diameter at breast height (dbh)) and distance to the shoreline $(\mathrm{m})$ were measured for each tree. General habitat characteristics such as slope and indicators of seabird nesting activity (burrows, guano, and feathers) were recorded. As these observations were made on September 12 and September 22 for Lucy and Rankine Islands, respectively, after the nesting season, we could not reliably differentiate active from inactive burrows.

There was no clear evidence for alternate nitrogen sources such as Bald Eagle (Haliaeetus leucocephalus) activity and North American River Otter (Lontra canadensis) latrines that could substantially influence nitrogen sources near the cored trees, although winddriven marine flotsam such as macrophytes could accentuate the input of nutrients to those trees near the shoreline. We suspect the influence is very limited, given that more permanent flotsam such as wood debris and plastic flotsam was common immediately above the high tide marks yet was absent higher in the areas where coring was done.

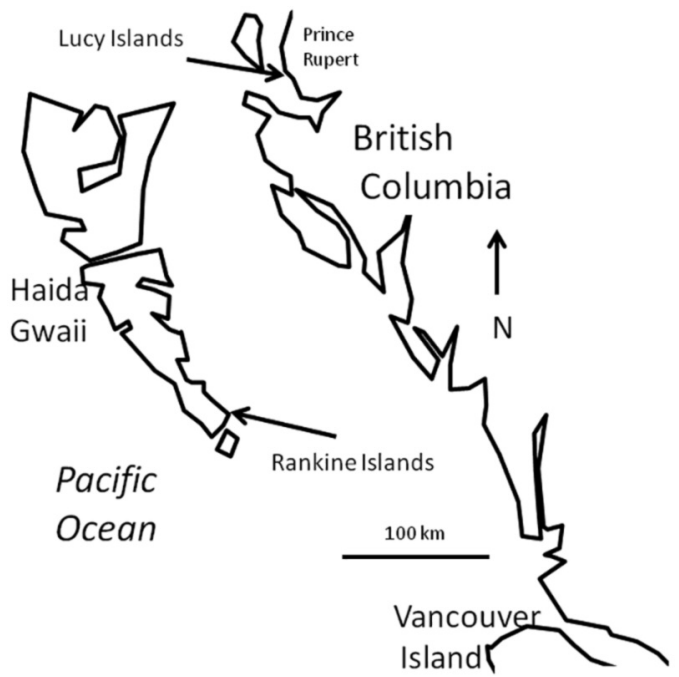

FIgURE 1. General location of Lucy and Rankine Islands in coastal British Columbia.

On each island, we chose trees to be cored along a transect perpendicular to the high tide mark across a sharp gradient in burrow densities. These included trees near the most central part of the islands, without burrows, through to trees closer to shore, where burrow entrances $(<2 \mathrm{~m}$ from the tree base) were most abundant ( $>10$ burrows per tree base). We assume that number of entrances generally correlates with number of burrows. As well, as much as possible, we also chose trees of similar size to reduce differences in root areas and depths, as nitrogen isotope signatures increase with soil depth (Koopmans et al. 1997).

At the Lucy Islands site (Lc), each of the 6 trees cored was situated within a flat zone on the southeastern region of the island. At $\sim 150 \mathrm{~m}$ from the waterline and $\sim 20 \mathrm{~m}$ elevation, 2 trees $50 \mathrm{~m}$ apart in an area without burrows were cored (identified as Lc2n and Lc3n) (Lc2n dbh $=0.56 \mathrm{~m}$, age $\sim 147$ years; Lc3n dbh = $0.65 \mathrm{~m}$, age $\sim 109$ years). At the intermediate location, $100 \mathrm{~m}$ from the waterline, burrows were present but uncommon ( $b=1-2$ burrows/tree base). Two trees in this area were cored at $100 \mathrm{~m}$ from the waterline, identified as Lc6b and Lc7b (Lc6b dbh $=0.56 \mathrm{~m}$, estimated age $\sim 81$ years; $\mathrm{Lc} 7 \mathrm{~b} \mathrm{dbh}=0.92 \mathrm{~m}$, age $\sim 70$ years). At the inner location, $50 \mathrm{~m}$ from the waterline and $\sim 10 \mathrm{~m}$ in elevation, burrow densities were high ( $b b=>10$ burrows per tree base). Here 2 further trees were cored, identified as Lc5bb and Lc1bb (Lc5bb dbh $=0.92 \mathrm{~m}$, age $\sim 107$ years; Lc1bb dbh $=1.18 \mathrm{~m}$, age $\sim 159 \mathrm{yrs}$ ). Each tree chosen for coring was the largest Sitka Spruce in the area and was approximately $50 \mathrm{~m}$ from the nearest cored tree.

At the Rankine Islands site, 6 trees (5 Sitka Spruce and 1 Western Hemlock) from the southeastern region of the large island, all within a zone $200 \mathrm{~m}$ wide along 
the slope, were cored. The control site, identified as $\mathrm{Rk} 4 \mathrm{n}$, was near the top of the island, where burrows were least common (Rk4n dbh $=0.91 \mathrm{~m}$, age $\sim 126 \mathrm{yrs}$ ). The location identified as Rk3b was $100 \mathrm{~m}$ to the southeast of $\mathrm{Rk} 4 \mathrm{n}$ on a $45^{\circ}$ slope with numerous burrows (Rk3b dbh $=1.27 \mathrm{~m}$, age $\sim 232$ years). The location identified as $\mathrm{Rk} 8 \mathrm{bb}(\mathrm{Rk} 8 \mathrm{bb} \mathrm{dbh}=0.92 \mathrm{~m}$, age $\sim 70$ years) was on the eastern edge of the island, which is the major site for burrows. Also, at this location, which had a high number of burrows, we cored a Western Hemlock, identified as Rk7WHbb. This tree had previously been metal tagged (CAAU Plot 3, Bearing Point D270) and is part of a British Columbia seabird inventory monitoring program begun in 1984 (Lemon, personal communication) (Rk7WHbb dbh $=1.08 \mathrm{~m}$, age $\sim 225$ years). Each of the cored trees was the largest within the area.

To examine potentially confounding associations between tree size and isotopic signatures, we also cored two Sitka Spruce saplings, identified as Rk4sn and Rk8sbb. Sapling Rk4sn was $3 \mathrm{~m}$ from the base of Rk4n. There were no burrows in this area $(\mathrm{Rk} 4 \mathrm{sn} \mathrm{dbh}=$ $0.048 \mathrm{~m}$, age $=16$ years). The second sapling was $2 \mathrm{~m}$ from Rk8bb. Burrows were abundant in this area $(\mathrm{Rk} 8 \mathrm{sbb} \mathrm{dbh}=0.11 \mathrm{~m}$, age $=11$ years $)$.

Cores were extracted with an increment borer (length $=40 \mathrm{~cm}$, diameter $=1.2 \mathrm{~cm}$; Haglöf Inc, Sweden) and placed in solid plastic tubes with netted ends. These were returned to the boat and stored vertically over a drying fan until they could be returned to the lab ( three weeks), where they were placed in a drying oven at $60^{\circ} \mathrm{C}$ for at least two to three weeks until dry and then stored at room temperature. Each core was sanded with progressively finer sandpaper until smooth and then digitally scanned at $1200 \mathrm{dpi}$.

For analyses of yearly growth, the total ring width was measured to the nearest $0.01 \mathrm{~mm}$ using WinDENDRO (Version 6.1D, 1998, Regent Instruments Inc., Sainte-Foy, Quebec) with visual checks for each software-defined ring position (Guay et al. 1992). The actual year assigned to specific rings is accurate on the outer reaches of most cores but becomes less reliable as one progresses towards the base of the core, due to ambiguous or missing rings. Using the dendrochronology program COFECHA (Holmes, 1983) we examined cross-correlations against a master dating chronology (Grissino-Mayer 2001) for each island and made marginal adjustments for missing or false rings in 4 of the 12 cores. Average correlations with the master chronology were relatively low (Lucy Islands site 0.29 , range among trees 0.0-0.42; Rankine Islands site -0.24 , range among trees $0.06-0.77$ ).

For nitrogen analyses, selected rings were recovered with a scalpel blade under a dissecting microscope. In both field and laboratory protocols, we avoided direct human skin contact to minimize contamination of the cores. Detailed methodology on isotope analyses is given in Reimchen et al. (2003). Each wood sample
$(\mathrm{N}=245)$ was individually ground to a fine powder on a Wig-L-Bug grinder (Crescent Dental Co., Chicago, 111). Thirty $\mathrm{mg}$ (accurate to within $0.05 \mathrm{mg}$ ) of each ring was packaged in a $5 \times 12 \mathrm{~mm}$ tin capsule.

Signatures of $\delta^{15} \mathrm{~N}$ and percentage nitrogen from powdered wood were determined after online combustion of samples in an elemental analyzer (ANCA-Hydra 20-20, PDZ Europa, Stable Isotope Facility, University of California-Davis, California). Combustion of the samples was achieved at $1050^{\circ} \mathrm{C}$ with a $40 \mathrm{~mL}$ oxygen injection and $\mathrm{Cr}_{2} \mathrm{O}_{3}$ catalyst. Reproducibility of isotopic values on replicated samples averaged $\pm 1.0 \%$.

Several recent publications suggest that removal of mobile nitrogen from the sapwood provides a more reliable isotopic proxy of the bound nitrogen in recent tree rings than total nitrogen (Hart and Classen 2003; Elhani et al. 2003). We analyzed both sapwood and heartwood but we excluded data from sapwood from the majority of our analyses and discuss primarily data from the heartwood rings. This provides a more reliable measure of any long-term trends in the uptake of nitrogen from the soil (Hietz et al. 2010). As well, we exclude analyses of percentage nitrogen during the last decade of growth, as nitrogen levels increase sharply at the start of the sapwood (Balster et al. 2009), usually near the early 1980 s in our cores.

We obtained yearly precipitation and temperature data from Environment Canada for a weather station on the Lucy Islands (1920-2000) and at Sandspit and Masset, Haida Gwaii (1940-2000), the latter representing the closest stations to the Rankine Islands. We also compared growth against Pacific climate oscillation (Mantua et al. 1997).

\section{Results}

\section{Tree growth}

At the Lucy Islands site, yearly growth rate of trees ranged from $0.1 \mathrm{~mm} /$ year to $15 \mathrm{~mm} /$ year (Figure 2). The two trees from locations with low burrow densities (Lc2n, Lc3n) had relatively little growth $(\sim 2 \mathrm{~mm} /$ year) from 1925 to 2000 . In contrast, trees from locations with high burrow densities, Lclbb and Lc5bb (which were $100 \mathrm{~m}$ from Lc2n and Lc3n), each had high growth rates during the 1930s (8-14 mm/year). This fell non-linearly to $2 \mathrm{~mm}$ /year in recent years. Lc5bb showed additional elevated growth $(\sim 6 \mathrm{~mm} /$ year) in the 1970s. This growth was not evident in Lc1bb.

The two trees from the location with intermediate burrow density (Lc6b, Lc7b) also showed moderately elevated growth in the early $1930 \mathrm{~s}$ ( $\sim 6 \mathrm{~mm} /$ year $)$. This fell rapidly in the late 1930s, concurrent with a similar reduction in the growth rate in Lc1bb and Lc5bb. Yearly growth of Lc6b remained low $(\sim 2 \mathrm{~mm} /$ year $)$ throughout the time period, while Lc7b showed significant increased growth in the 1970s before falling to 2000 . 


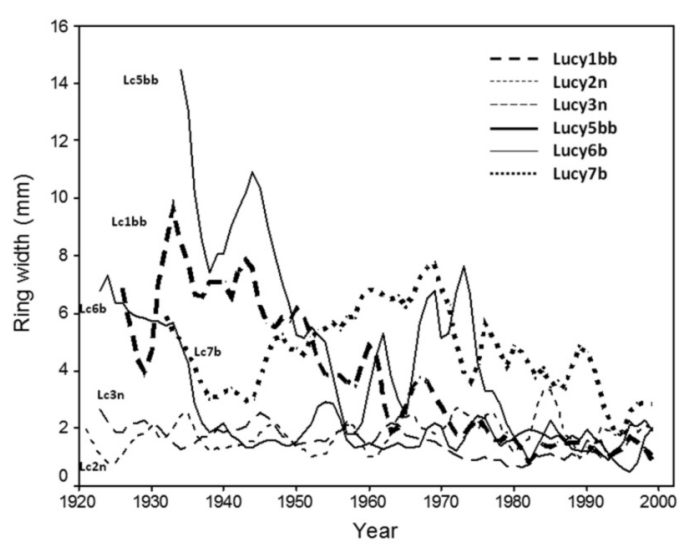

FIGURE 2. Yearly tree ring growth $(\mathrm{mm})$ for Sitka Spruce (Picea sitchensis) at the seabird colony on the Lucy Islands, British Columbia, 1920-2000, from cores made in September 2000. Lines represent three-point moving average of yearly growth for six trees. Tree code (Lc\#) shows relative seabird burrow abundance at base of tree: no burrows $-\mathrm{n} ; 1-2$ burrows $-\mathrm{b} ;>10$ burrows-bb.

At the Rankine Islands site, there were substantial fluctuations in tree growth over time, with an irregular periodicity of 10 to 15 years (Figure 3 ). The peak growth in the mid-1970s was generally synchronous among the four large trees $(r>0.48$ for each comparison), but there was no overall consistency among the four trees for the period 1925-2000 $(P>0.05)$. The highest growth rate (range $5-11 \mathrm{~mm} /$ year) occurred in Rk8bb, which was at the location with the highest seabird burrow densities. The single Western Hemlock

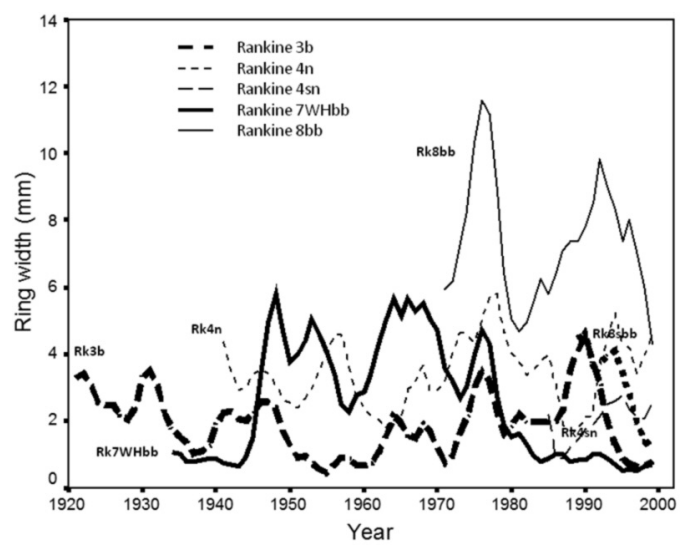

FIGURE 3. Yearly tree ring growth (mm) for conifers at the seabird colony on the Rankine Islands, British Columbia, 1920-2000, from cores made in September 2000. Lines represent three-point moving average of yearly growth. Tree code ( $\mathrm{Rk \# )}$ shows relative seabird burrow abundance at base of tree: no burrows - n; 1-2 burrows$\mathrm{b} ;>10$ burrows - bb. All trees are Sitka Spruce (Picea sitchensis) except Rk7whbb, which is Western Hemlock, Tsuga heterophylla).
(Rk7whbb), adjacent to $\mathrm{Rk} 8 \mathrm{bb}$, had low growth rates ( $\sim 1 \mathrm{~mm} /$ year) in the 1940 s but this increased sharply thereafter and varied between $2 \mathrm{~mm} /$ year and $6 \mathrm{~mm} /$ year before falling to $\sim 1 \mathrm{~mm} /$ year from 1980 to 2000 .

The two saplings used as size controls from locations with low and high burrow densities (Rk4sn and $\mathrm{Rk} 8 \mathrm{sbb}$, respectively) each had approximately one-half the annual growth rate of their respective larger counterparts. They exhibited a strong correlation in yearly trends with their larger counterparts $(r>0.75, P<0.01)$ but not with each other $(r=-0.3, P=0.35)$.

\section{Nitrogen isotopes}

Isotopic signatures among trees varied spatially at the two sites. Average $\delta^{15} \mathrm{~N}$ enrichment (excluding sapwood) ranged from $1 \%$ to $10 \%$ among the 12 trees and was higher on the Lucy Islands site than on the Rankine Islands site $\left(\delta^{15} \mathrm{~N}=6.5\right.$ and 4.5 , respectively; $F_{1}=27.1, P<0.001$ ) (Figure 4). Range among individual rings was large on both islands (Lucy Islands site $-1.7 \%$ to $17.4 \%$; Rankine Islands site $-3.9 \%$ to $10.9 \%)$.

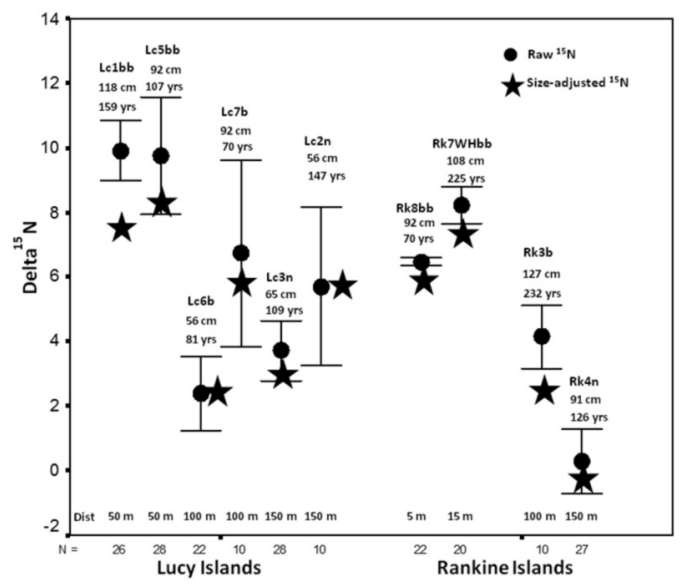

FIGURE 4. Mean $\delta^{15} \mathrm{~N}$ signatures in yearly growth rings from conifers at two seabird colonies (one in the Lucy Islands and one in the Rankine Islands) in northern British Columbia in September 2000. For each island, trees are arranged from locations with abundant burrows to sites with no burrows. $\mathrm{N}=$ number of individual rings analyzed per tree. Dist $=$ tree distance $(\mathrm{m})$ from the high tide mark. $\mathrm{DBH}=$ diameter $(\mathrm{m})$ at breast height; Age = actual or estimated age of tree; Star = Isotopic signatures standardized to the smallest tree dbh in each colony. Tree code shows relative seabird burrow abundance at base of tree: no burrows $-\mathrm{n}$; 1-2 burrows - $b ;>10$ burrows - $b b$.

Isotopic enrichment was highest in sites where burrow density was the highest and lowest $100 \mathrm{~m}$ further inland, where burrows were uncommon (Lucy Islands site $F_{1,4}=5.0, P=0.09$; Rankine Islands site $F_{1,4}=28.7$, $P=0.006$ ). Although the number of trees sampled is too low to allow useful statistical interpretations to be 
made, the spatial trends in $\delta^{15} \mathrm{~N}$ at the Lucy Islands site co-varied with tree size, as the largest and smallest trees showed the highest and lowest isotopic signatures, respectively (Figure 4). The spatial trends at the Rankine Islands site did not co-vary with tree size.

There was extensive temporal variation in isotopic signatures. The majority of trees exhibited increased $\delta^{15} \mathrm{~N}$ enrichment from 1920 to 2000 (Figures 5 and 6). Nine of the ten regression slopes were significantly different from zero $(P<0.001$ in all cases $)$, and in each island there were statistical differences among slopes (Lucy Islands site ANCOVA interaction term $\delta^{15} \mathrm{~N}$. Year $F_{5}=9.6, P<0.01$; Rankine Islands site $F_{3}=38.4$, $P<0.01)$.

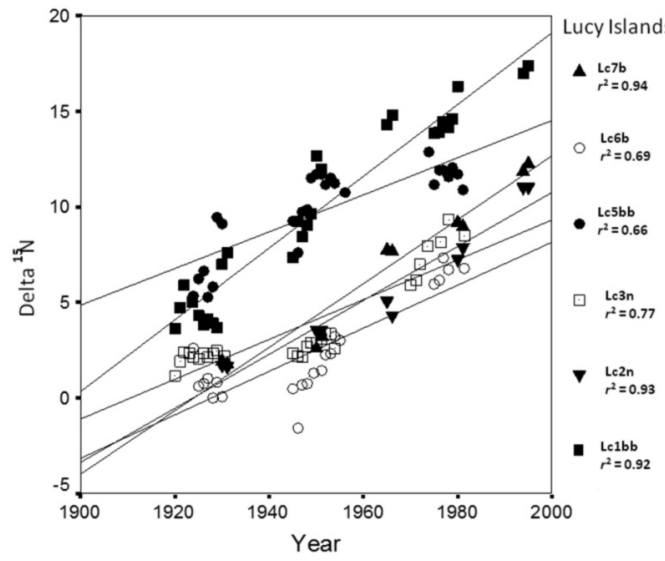

Figure 5. Temporal trends in $\delta^{15} \mathrm{~N}$ signatures in yearly tree rings for the seabird colony on the Lucy Islands in coastal British Columbia, 1920-2000, from cores made in September 2000. Best-fit linear regression shown for each core. Tree code shows relative seabird burrow abundance at base of tree: no burrows - $\mathrm{n} ; 1-2$ burrows - $\mathrm{b} ;>10$ burrows - bb.

There were no consistent differences in slopes between the locations with high burrow densities and the locations with no burrows, although the intercept was higher in the former. The average enrichment over this 70 -year period was $\sim 10 \%$ for the Lucy Islands site and $\sim 5 \%$ for the Rankine Islands site. Exclusion of sapwood years $(>1980)$ did not seriously alter this trend, as 8 of 10 regression slopes remained highly significant $(P<0.01)$.

The increased isotopic enrichment over time in most trees also co-varied with yearly increases in tree size. We tried to evaluate directly the effects of size by comparing yearly isotopic signatures in a large tree and a sapling from the same microsite (within $3 \mathrm{~m}$ ). This showed enrichment in the larger trees both at locations with high burrow densities and at locations with low burrow densities (Figure 7). In the location with high burrow densities, enrichment of the large tree (Rk8bb) was on an average $4.9 \%$ o higher than in the adjacent

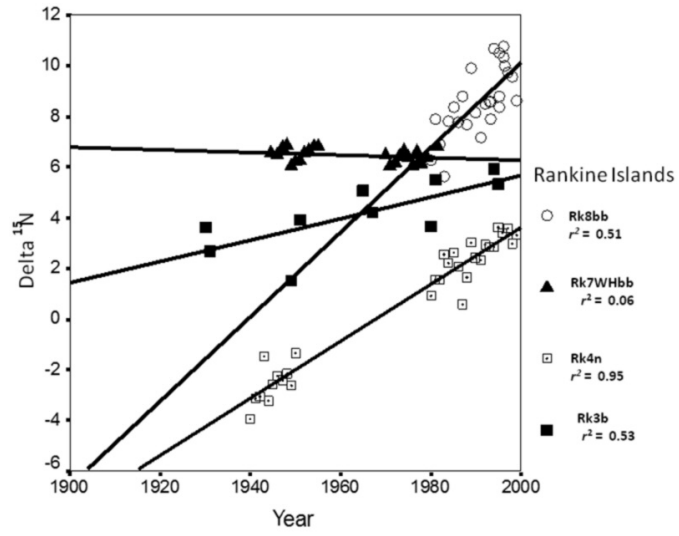

FIgURE 6. Temporal trends in $\delta^{15} \mathrm{~N}$ signatures in yearly tree rings for the seabird colony on the Rankine Islands, coastal British Columbia, 1920-2000, from cores made in September 2000. Best-fit linear regression shown for each core. Tree code shows relative seabird burrow abundance at base of tree: no burrows - $n$; $1-2$ burrows - $b ;>10$ burrows - bb.

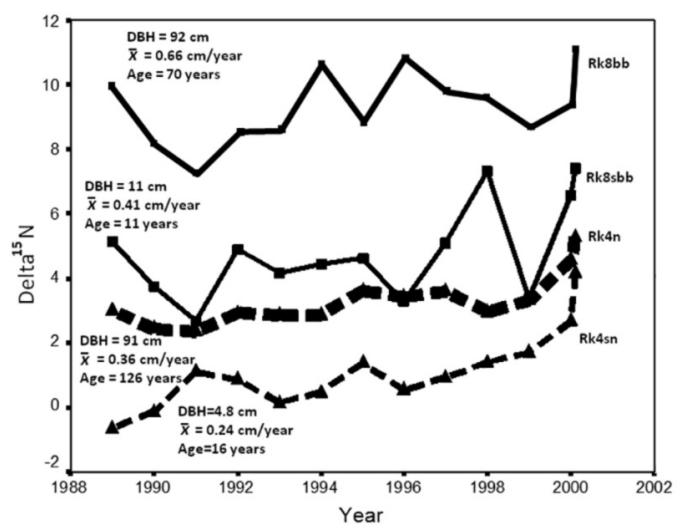

FIGURE 7. Yearly comparison of $\delta^{15} \mathrm{~N}$ signatures in paired large and small trees from locations with high burrow densities and no burrows on the Rankine Islands, British Columbia, 1988-2000. Graph shows data from two large Sitka Spruce (Picea sitchensis) (Rk4n and Rk8bb), each with a companion Sitka Spruce sapling as a size control. Rk4sn was located $3 \mathrm{~m}$ from the base of Rk4n. Rk8sbb was located $2 \mathrm{~m}$ from the base of $\mathrm{Rk} 8 \mathrm{bb} ; \mathrm{DBH}=$ diameter at breast height; = average yearly ring growth.

sapling (Rk8sbb) among the overlapping years (paired $t=13.5, P<0.001)$. At the location with low burrow densities, enrichment in the large tree (Rk4n) was on average $2.5 \%$ higher than in the adjacent sapling $(\mathrm{Rk} 4 \mathrm{sn})$ among the overlapping years (paired $t=11.5$, $P<0.001)$.

The close physical proximity of each large tree and sapling in a pair allowed us to compare the temporal 
trends in isotopic signatures over the decade. These were strongly correlated in the pair from the location with high burrow densities $(r=0.84, P<0.001)$ but were only marginally but not significantly correlated for the location with low burrow densities $(r=0.54$, $P<0.06$ ). If we assume that these paired comparisons characterize the broader relationship between tree size and relative isotopic signatures, the average $\delta^{15} \mathrm{~N}$ isotopic enrichment would be $0.045 \%$ per $\mathrm{cm}$ of increased tree diameter (range $0.029-0.60 \%$ ). Consequently, isotopic signatures were size-standardized (assuming an increment of $0.045 \% / \mathrm{cm})$ to the smallest tree $(\mathrm{dbh}=$ $56 \mathrm{~cm})$.

This correction reduces the extent of enrichment among the larger trees but does not remove the general trends in the spatial data, which showed elevated signatures in the trees from [the areas with high burrow densities in both the Lucy Islands site and the Rankine Islands site (Figure 4). Similarly, the temporal trends from the 1930s to the recent past are slightly moderated by removing tree size effects. However, for all trees (apart from $\mathrm{Rk} 7 \mathrm{whbb}$ ), slopes remain positive, indicating general enrichment in signatures over the last seven to eight decades.

We assessed whether yearly differences in ring $\delta^{15} \mathrm{~N}$ were associated with yearly difference in the growth of each tree. For each locality, we computed the common regression slope between $\delta^{15} \mathrm{~N}$ enrichment and year for all cores combined and extracted the standardized $\delta^{15} \mathrm{~N}$ residuals for each core. Comparable residuals for each core were extracted for yearly growth based on the common regression line between ring and year. Bivariate plots of these residuals (Figure 8 ) yielded a significant positive correlation $(P<0.05)$ in both colonies, showing that elevated growth tends to occur with increased isotopic enrichment.

On the assumption that some proportion of the levels of $\delta^{15} \mathrm{~N}$ in each tree ring is a product of yearly differences in guano input, we predicted that increased $\delta^{15} \mathrm{~N}$ levels would be correlated with increased total nitrogen in the rings. This was confirmed, as there was a positive correlation in 11 of the 12 trees $(r>0.4)$ between these variables ( 9 of 11 with $P<0.05$ ). The correlations may be inflated because of the sharp increase in nitrogen levels in the sapwood rings (data not shown) and the general enrichment of $\delta^{15} \mathrm{~N}$ from the past to the present (Figures 5 and 6). Excluding the data from the sapwood rings removes the relationship in the Rankine Islands site (all $r<0.1, P>0.5$ ), but there remains a significant $(P<0.01)$ positive correlation in 4 of the 6 trees from the Lucy Islands site $(r>0.44)$ between percentage $\mathrm{N}$ and $\delta^{15} \mathrm{~N}$ enrichment.

Differences in average yearly precipitation and temperature could also be expected to influence relative tree growth. Yearly precipitation and tree growth were correlated $(P<0.05)$ in 4 of the 12 trees $(\mathrm{Lc} 1 \mathrm{bb}, \mathrm{Lc} 3 \mathrm{n}$, Lc5bb, and Rk8sbb), but in each of these, there was an inverse relationship. Yearly temperature and growth



FIGURE 8. Relationship between average residuals for yearly tree growth and residuals of nitrogen isotope signatures on two seabird colonies (one on the Lucy Islands and one on the Rankine Islands), coastal British Columbia. Residuals extracted from linear regression between $\delta^{15} \mathrm{~N}$ and year of growth separated for locality (see Figures 4 and 5). Error bars show standard deviation. Tree code shows relative seabird burrow abundance at base of tree: $n-$ no burrows; $b-1$ or 2 burrows; bb $\longrightarrow 10$ burrows.

were significantly positively correlated in three trees (Lc2n, Lc3n, and Lc5bb) and negatively correlated in Rk7whbb $(P<0.05)$. Overall comparisons (ANOVA with temperature and precipitation as covariates) yielded a significant negative effect for precipitation and growth $(F=12.4, P<0.001)$ and no effect for temperature and growth $(F=2.1, P=>0.15)$.

We also examined growth in relation to the Pacific Decadal Oscillation for all the trees. Two of the 12 trees (one on each island) showed a significant correlation $(P<0.01)$ and in both cases it was negative.

\section{Discussion}

We evaluated the potential application of tree ring growth and nitrogen signatures as indicators of current and historical trends in seabird activity. Because the amount of seabird guano deposited in a colony should on average reflect the abundance and density of seabird activity, we predicted that yearly radial growth of trees would be accentuated in regions of high burrow density. Our data are consistent with this prediction and are similar to previous studies of seabird colonies in Japan (Mizota 2009; Mizota et al. 2011).

Statistical removal of tree size, which exhibits a modest positive association with yearly growth, did not undo the spatial associations with seabird burrow occurrence. Consequently, we predicted that historical differences in growth rate among trees from high burrow densities relative to nearby control trees where burrows were absent should in part reflect general differences in seabird activity. Based on this, we infer that, at the Lucy Islands site, there was a substantive reduction in seabird activity from 1920 to the 1960 s and a partial 
rebound in the late 1960s and early 1970s, followed by a continued decline to the 1990 s. This may be correlated with the general reduction in seabird numbers observed in more southern colonies over the last century (Harfenist et al. 2002; Gaston et al. 2009), but the apparent decline might also be associated with human disturbance, such as road construction in the forest habitat during the 1900s (Graham 1986).

Corresponding data from the Rankine Islands site show a trend consistent with the Lucy Islands site for the spatial data, but for temporal data, trees from both low and high burrow microsites exhibited a 10- to 15 year periodicity in growth over the same time period and might reflect climatic influences on seabird nesting densities (for example, Bertram et al. 2009).

Seabird guano is greatly enriched in ${ }^{15} \mathrm{~N}$ (Mitzutani and Wada 1988), and we predicted that ${ }^{15} \mathrm{~N}$ enrichment would occur at higher levels in trees from regions of high burrow density. This was confirmed in both colonies and is concordant with other research on ground vegetation in California and Alaskan seabird colonies (Polis et al. 1997; Anderson and Polis 1998; Anderson et al. 2008; Wainright et al. 1998) and tree-ring analyses from seabird colonies in New Zealand (Holdaway et al. 2007) and Japan (Mizota 2009; Mizota et al. 2011). Enrichment of $\delta^{15} \mathrm{~N}$ in the sapwood ranged from approximately $10 \%$ in the non-burrow sites to $17 \%$ where burrows were prevalent. The latter enrichment is about $10 \%$ higher than that observed in tree rings from salmon rivers (Reimchen et al. 2003) but is comparable to levels observed in soil and foliar tissue from seabird colonies (Barrett et al. 2005; Wait et al. 2005; Mizota 2009).

Our observation of a major reduction in growth of trees from 1930 to the recent past from the locations with high burrow densities at the Lucy Islands site led us to suspect that ${ }^{15} \mathrm{~N}$ would also decrease over the same time period. But, in complete contrast to this prediction, there was a general increase in ring $\delta^{15} \mathrm{~N}$ enrichment in 9 of 10 trees, common trends that were independent of both seabird burrow density and current size of trees.

Similar temporal increases in isotopic signatures have been reported in studies unrelated to seabirds (Feliksik and Wilczyński 2007; Weber et al. 2008; Couto-Vázquez and González-Prieto 2010) — but see Penuelas and Estiarte (1997) — including the multiple trees on salmon rivers from throughout coastal British Columbia (TER, unpublished data). Such geographically broad temporal trends suggest large-scale changes in nitrogen sources. For example, total nitrogen levels have increased over the last 100 years throughout much of the globe (Vitousek et al. 1997). This could have contributed to our trends if $\delta^{15} \mathrm{~N}$ enrichment also increased, yet recent empirical data from nitrate in Greenland ice cores show the opposite trend, as there has been a progressive decrease in ${ }^{15} \mathrm{~N}$ from atmospheric deposition over the last 300 years (Hastings et al.
2009). Alternatively, the common trends among the trees could relate to size-related changes in nitrogen cycling. Weber et al. (2008) suggest that lower $\delta^{15} \mathrm{~N}$ enrichment in younger trees is the result of their access to the needle litter in surface soils rather than the deeper nitrogen sources, which are $\delta^{15} \mathrm{~N}$ enriched as a consequence of decomposition in the soils.

Perhaps, independent of soil depth, the total availability of the nitrogen pool is relevant, as higher input of nitrogen will result in greater fractionation and reduced uptake of ${ }^{15} \mathrm{~N}$ (Handley et al. 1999). Consequently, if saplings or other small trees are exposed to levels of nitrogen adequate for larger counterparts but surplus to their own requirements, increased fractionation would be expected. This might contribute to the $\delta^{15} \mathrm{~N}$ depletion observed in the younger ages in the trees.

Our comparisons of $\delta^{15} \mathrm{~N}$ depletion in two saplings and their much larger counterparts at the same microsite were consistent with the suggestion that smaller trees show greater isotopic fractionation than their large counterparts. Although we estimated a calibration of about $0.045 \%$ per $\mathrm{cm}$ of tree, this did not substantially modify the increase in $\delta^{15} \mathrm{~N}$ signatures over the last 70 years. Currently, our data are not sufficient to identify whether these increases are atmospheric or more explicitly associated with seabird activity. The positive correlation between isotopic signatures and growth rate suggests access to an increased nitrogen pool.

Seabird populations are generally thought to have suffered a substantive decline over the last century, including those from the north Pacific (Campbell et al. 1990; Harfenist et al. 2002; Gjerdrum et al. 2003; Bertram et al. 2009; González-Solís and Shaffer 2009; International Union for Conservation of Nature 2009; Wolf et al. 2010). In British Columbia, seabird numbers have been monitored at several locations over the last three decades and show a slight reduction in the southern regions and a slight positive trend in northern British Columbia (Gaston et al. 2009).

Although the number of trees sampled in this study is small, the results show major heterogeneity in tree ring growth and nitrogen signatures over microgeographical gradients in abundance of seabird burrows. In this context, the growth data but not the nitrogen isotope data for the Lucy Islands site suggest a substantial reduction in seabird abundance over the last century (Gaston et al. 2009) but not for the more distant Rankine Islands colony in the Haida Gwaii archipelago, where temporal oscillation in activity is suggested.

These preliminary results, which are the first application of tree growth and isotopic proxies to seabird colonies in western Canada, supplement other recent studies on seabird activity in the western Pacific (Holdaway et al. 2007; Mizota et al. 2011). Despite the unresolved issues, such as nitrogen translocation (Balster et al. 2009), climatic variability (Bertram et al. 2005), 
and trophic differentiation among alcids, we feel a broader coring grid with appropriate choice of target and adjacent control trees will provide seabird researchers with an additional tool to estimate the historical chronology and spatial distribution of seabird activity within and among colonies.

\section{Acknowledgements}

We acknowledge B. Foster and D. Klinka for coring assistance as well as C. Fox and B. Deagle for comments on the manuscript and M. Lemon for providing historical data on the Rankine Islands. This work was carried out during field surveys with funding from the David Suzuki Foundation, Vancouver, British Columbia, and an operating grant from the Natural Sciences and Engineering Research Council of Canada to TER (NRC 2354).

\section{Literature Cited}

Anderson, W. B., and G. A. Polis. 1998. Marine subsidies of island communities in the Gulf of California: evidence from stable carbon and nitrogen isotopes. Oikos 81: 75-80.

Anderson, W. B., D. A. Wait, and P. Stapp. 2008. Resources from another place and time: responses to pulses in a spatially subsidized system. Ecology 89: 660-670.

Balster, N. J., J. D. Marshall, and M. Clayton. 2009. Coupling tree-ring $\delta^{13} \mathrm{C}$ and $\delta^{15} \mathrm{~N}$ to test the effect of fertilization on mature Douglas-fir (Pseudotsuga menziesii var. glauca) stands across the Interior northwest, USA. Tree Physiology 29: 1491-1501.

Barrett, K., W. B. Anderson, D. A. Wait, L. G. Grismer, G. A. Polis, and M. D. Rose. 2005. Marine subsidies alter the diet and abundance of insular and coastal lizard populations. Oikos 109: 145-153.

Bertram, D. F., A. Harfenist, and A. Hedd. 2009. Seabird nestling diets reflect latitudinal temperature-dependent variation in availability of key zooplankton prey populations. Marine Ecology Progress Series 393: 199-210.

Bukata, A. R., and T. K. Kyser. 2007. Carbon and nitrogen isotope variations in tree-rings as records of perturbations in regional carbon and nitrogen cycles. Environmental Science and Technology 41: 1331-1338.

Campbell, R. W., N. K. Dawe, I. McTaggart-Cowan, J. M. Cooper, G. W. Kaiser, and M. C. E. McNall. 1990. Nonpasserines: Diurnal birds of prey through woodpeckers. Vol. II of The Birds of British Columbia. Royal British Columbia Museum, Victoria, British Columbia, and Canadian Wildlife Service, Ottawa, Ontario.

Couto-Vázquez, A., and S. J. González-Prieto. 2010. Effects of climate, tree age, dominance and growth on $\delta^{15} \mathrm{~N}$ in young pinewoods. Trees 24: 507-514.

Drake, D. C., and R. J. Naiman. 2007. Reconstruction of Pacific salmon abundance from riparian tree-ring growth. Ecological Applications 17: 1523-1542.

Drake, D. C., R. J. Naiman, and J. S. Bechtold. 2006. Fate of nitrogen in riparian forest soils and trees: an ${ }^{15} \mathrm{~N}$ tracer study simulating salmon decay. Ecology 87: 1256-1266.

Elhani, S., B. F. Lema, B. Zeller, C. Brechet, J. M. Guehl, and J. L. Dupouey. 2003. Inter-annual mobility of nitrogen between beech rings: a labeling experiment. Annals of Forest Science 60: 503-508.
Ellis, J. C. 2005. Marine birds on land: a review of plant biomass, species richness, and community composition in seabird colonies. Plant Ecology 181: 227-241.

Feliksik, E., and S. Wilczyński. 2007. Tree-ring chronology as a source of information on susceptibility of Sitka Spruce to climatic conditions of Pomerania (northern Poland). Geochronometria 30: 79-82.

Gaston, A. J., and S. B. Dechesne. 1996. Rhinoceros Auklet (Cerorhinca monocerata). No. 212 in The Birds of North America. Edited by A. Poole. Cornell Lab of Ornithology, Ithaca, New York.

Gaston, A. J., D. F. Bertram, A. W. Boyne, J. W. Chardine, G. Davoren, A. W. Diamond, A. Hedd, W. A. Montevecchi, J. M. Hipfner, M. J .F. Lemon, M. L. Mallory, J. Rail, and G. J. Robertson. 2009. Changes in Canadian seabird populations and ecology since 1970 in relation to changes in oceanography and food webs. Environmental Reviews 17: 267-286.

Gjerdrum, C, A. M. J. Vallée, C. C. St. Clair, D. F. Bertram, J. L. Ryder, and G. W. Blackburn. 2003. Tufted puffin reproduction reveals ocean climate variability. Proceedings of the National Academy Science USA 100: 9377-9382.

González-Solís, J., and S. A. Shaffer. 2009. Introduction and synthesis: spatial ecology of seabirds at sea. Marine Ecology Progress Series 391: 117-120.

Graham, D. 1986. Lights of the Inside Passage: A History of British Columbia's Lighthouses and their Keepers. Harbour Publishing, Madeira Park, British Columbia.

Grissino-Mayer, H. D. 2001. Evaluating crossdating accuracy: a manual and tutorial for the computer program COFECHA. Tree-ring Research 57: 205-221.

Guay, R., R. Gagnon, and H. Morin. 1992. A new automatic method and interactive tree ring measurement system based on a line scan camera. Forestry Chronicles 68: 138-141.

Handley, L. L., A. T. Austin, G. R. Stewart, D. Robinson, C. M. Scrimgeour, J. A. Raven, T. H. E. Heaton, and S. Schmidt. 1999. The ${ }^{15} \mathrm{~N}$ natural abundance $\left(\delta^{15} \mathrm{~N}\right)$ of ecosystem samples reflects measures of water availability. Australian Journal of Plant Physiology 26: 185-199.

Harfenist, A., N. A. Sloan, and P. M. Bartier. 2002. Marine bird baseline to 2000 and marine bird-related management issues throughout the Haida Gwaii region. Vol. III of Living Marine Legacy of Gwaii Haanas. Parks Canada Technical Reports in Ecosystem Science No. 36.

Hart, S. C., and A. T. Classen. 2003. Potential for assessing long-term dynamics in soil nitrogen availability from variations in $\delta^{15} \mathrm{~N}$ of tree rings. Isotopes in Environmental Health Studies 39: 15-28.

Hastings, M. G., J. C. Jarvis, and E. J. Steig. 2009. Anthropogenic impacts on nitrogen isotopes of ice-core nitrate. Science 324: 1288.

Hawke, D. J. 2004. Maximum possible age of a petrel breeding colony near Punakaiki (South Island, New Zealand) from radiocarbon and stable isotope analysis of soil. Journal of the Royal Society of New Zealand 34: 1-7.

Hietz, P., O. Dünisch, and W. Wanek. 2010. Long-term trends in nitrogen isotope composition and nitrogen concentration in Brazilian rainforest trees suggest changes in nitrogen cycle. Environmental Science and Technology 44 : 1191-1196.

Holdaway, R. N., D. J. Hawke, O. M. Hyatt, and G. C. Wood. 2007. Stable isotopic $\delta^{15} \mathrm{~N}, \delta^{13} \mathrm{C}$ analysis of wood 
in trees growing in past and present colonies of burrownesting seabirds in New Zealand. I. $\delta^{15} \mathrm{~N}$ in two species of conifer (Podocarpaceae) from a mainland colony of Westland petrels (Procellaria westlandica), Punakaiki, South Island. Journal of the Royal Society of New Zealand 37: 75-84.

Holmes, R. L. 1983. Computer-assisted quality control in tree-ring dating and measurements. Tree-Ring Bulletin 43: 69-78.

International Union for Conservation of Nature (IUCN). 2009. IUCN red list of threatened species. http://www.iucn redlist.org.

Koopmans, C. J., D. Van Dam, A. Tietema, and J. M. Verstraten. 1997. Natural ${ }^{15} \mathrm{~N}$ abundance in two nitrogen saturated forest ecosystems. Oecologia 111: 470-480.

Mantua, N. J., S. R. Hare, Y. Zhang, J. M. Wallace, and R. C. Francis. 1997. A Pacific interdecadal climate oscillation with impacts on salmon production. Bulletin of the American Meteorological Society 78: 1069-1079.

Mathewson, D. D., M. D. Hocking, and T. E. Reimchen. 2003. Nitrogen uptake in riparian plant communities across a sharp ecological boundary of salmon density. BMC Ecology 2003: 4.

Mizutani, H., and E. Wada. 1988. Nitrogen and carbon isotope ratios in seabird rookeries and their ecological implications. Ecology 69: 340-349.

Mitzutani, H., Y. Kabaya, P. J. Moors, T. W. Speir, and G. L. Lyon. 1991. Nitrogen isotope ratios identify deserted seabird colonies. Auk 108: 960-964.

Mizota, C. 2009. Nitrogen isotopic patterns of vegetation as affected by breeding activity of Black-tailed Gull (Larus crassiostris): a coupled analysis of feces, inorganic soil nitrogen and flora. Applied Geochemistry 24: 2027-2033.

Mizota C., M. L. Caceres, T. Yamanaka, and Y. Nobori. 2011. Differential response of two spp. to avian nitrogen input as revealed by nitrogen isotope analysis for tree rings. Isotopes in Environmental and Health Studies 47: 62-70.

Penuelas, J., and M. Estiarte. 1997 Trends in plant carbon concentration and plant demand for $\mathrm{N}$ throughout this century. Oecologia 109: 69-73.

Polis, G. A., W. P. Anderson, and R. D. Holt. 1997. Toward an integration of landscape and food web ecology: the dynamics of spatially subsidized food webs. Annual Review of Ecology and Systematics 28: 289-316.

Reimchen, T. E. 2000. Some ecological and evolutionary aspects of bear-salmon interactions in coastal British Columbia. Canadian Journal of Zoology 78: 448-457.
Reimchen, T. E. 2001. Salmon nutrients, nitrogen isotopes and coastal forests. Ecoforestry 16: 13-17.

Reimchen, T. E., D. D. Mathewson, M. D. Hocking, J. Moran, and D. Harris. 2003. Isotopic evidence for enrichment of salmon-derived nutrients in vegetation, soil and insects in riparian zones in coastal British Columbia. American Fisheries Society Symposium 34: 59-69.

Robinson, D. $2001 . \delta^{15} \mathrm{~N}$ as an integrator of the nitrogen cycle. Trends in Ecology and Evolution 16: 153-162.

Rodway, M. S. 1991. Status and conservation of breeding seabirds in British Columbia. Pages 43-102 in Seabird Status and Conservation: A Supplement. Edited by J. P. Croxall. International Council for Bird Preservation Technical Publication No. 11.

Schulze, E. D., F. S. Chapin, and G. Gebauer. 1994. Nitrogen nutrition and isotope differences among life forms at the northern treeline of Alaska. Oecologia 100: 406-412.

Vitousek, P. M., J. D. Aber, R. W. Howarth, G. E. Likens, P. A. Matson, D. W. Schindler, W. H. Schlesinger, and D. G. Tilman. 1997. Human alteration of the global nitrogen cycle: sources and consequences. Ecological Applications 7: 737-750.

Wainright, S. C., J. C. Haney, C. Kerr, A. N. Golovkin, and M. V. Flint. 1998. Utilization of nitrogen derived from seabird guano by terrestrial and marine plants at St. Paul, Pribilof Islands, Bering Sea, Alaska. Marine Biology 131: 63-71.

Wait D. A., D. P. Aubrey, and W. B. Anderson. 2005. Seabird guano influences on desert islands: soil chemistry and herbaceous species richness and productivity. Journal of Arid Environments 60: 681-695.

Weber, P., R. Bol, L. Dixon, and R. D. Bardgett. 2008. Large old trees influence patterns of $\delta^{13} \mathrm{C}$ and $\delta^{15} \mathrm{~N}$ in forests. Rapid Communications in Mass Spectrometry 22: 16271630.

Wilkinson, C. E., M. D. Hocking, and T. E. Reimchen. 2005. Uptake of salmon-derived nitrogen by mosses and liverworts in coastal British Columbia. Oikos 108: 85-98.

Wolf, S. G., M. A. Snyder, W. J. Sydeman, D. F. Doaks, and D. A. Croll. 2010. Predicting population consequences of ocean climate change for an ecosystem sentinel, the seabird Cassin's Auklet. Global Change Biology 16: 1923-1935.

Received 29 January 2013

Accepted 30 April 2013 